\title{
MENGGAGAS PENERAPAN PENGAJARAN TENTANG AKHIR ZAMAN DALAM PENDIDIKAN AGAMA KRISTEN DI TINGKAT SEKOLAH DASAR DAN MENENGAH PERTAMA \\ Bimo Setyo Utomo ${ }^{l}$
}

\begin{abstract}
Abstraksi
Eskatologi, khususnya dalam tradisi gereja kita merupakan salah satu topik yang terabaikan. Bahkan dalam pendidikan agama kristen di sekolah, kita dapat melihat tidak ada topik khusus mengenai eskatologi.Topik tentang eskatologi sangat penting untuk diajarkan kepada siswa di sekolah agar mereka dapat mempersiapkan diri dengan sebaik-baiknya untuk menyambut kedatangan Tuhan Yesus yang kedua kali. Dalam pengajaran Pendidikan Agama Kristen (PAK) di sekolah, seharusnya topik atau pelajaran ini mendapat perhatian dan alokasi waktu yang cukup. Melalui topik atau pelajaran ini diharapkan dapat memperkuat keimanan siswa; menolong siswa untuk merubah sikap yang tidak sesuai dengan kehendak Allah dan menanamkan dalam diri siswa bahwa kelak Tuhan Yesus akan datang untuk yang kedua kalinya.
\end{abstract}

Kata kunci: eskatologi, akhir zaman, kedatangan Yesus yang kedua, Pendidikan Agama Kristen, Sekolah Dasar, Sekolah Menengah Pertama

\section{Initiating the Implementation of Eschatology onChristian Religious Education in Elementary School and Junior High School}

\begin{abstract}
Eschatology, particularly in the tradition of our church is one of the neglected topic. Even, in Christian religious education in schools, we can see there is no specific topic about eschatology.The topic of eschatology is very important to be taught to students in schools, so that they can prepare as well as possible for the Lord Jesus' second coming. This topic should have received attention and allocation on sufficient time. This topic is expected to strengthen students'faith, helping them exchanging attitudes which are not in accordance with the will of God and convince that one day the Lord Jesus shall come.
\end{abstract}

Keyword: escchatology, last day, second coming, Christian Religious Education, Elementary School, Junior High School

${ }^{1}$ STT Bethany Surabaya 
PENDAHULUAN

Pelajaran tentang akhir zaman (eskatologi), merupakan salah satu dasar dari iman Kristen, sehingga pelajaran ini perlu diketahui, diajarkan dan diimani oleh setiap umat Tuhan termasuk kepada muridmurid di sekolah. Namun karena banyaknya pendapat dan tafsiran mengenai pelajaran kedatangan Tuhan Yesus kedua kali, maka sangatlah perlu mengetengahkan pelajaran ini secara benar dan tepat seperti apa yang dikatakan oleh Firman Allah.

Kekurangpahaman dalam penguasaan pelajaran tentang kedatangan Tuhan Yesus kedua kali bisa menyebabkan penafsiran yang menyimpang bahkan bertolak belakang dengan Firman Allah itu sendiri. Tidak sedikit kesalahan dalam penafsiran dan penyajian pelajaran tentang kedatangan Tuhan Yesus kedua kali, bukannya membangkitkan gairah, semangat dan harapan, damai dan sejahtera untuk menyambut kedatangan Yesus yang kedua kali, sebaliknya justru mendatangkan perasaan takut, gelisah, bingung dan penyesatan. Contoh, pada awal tahun 1992, telah berkembang pengajaran yang mengajarkan bahwa pada tanggal 28 Oktober 1992 Tuhan Yesus akan datang kedua kali. Namun kenyataannya, sampai sekarang pun Tuhan Yesus belum datang. Akibatnya adalah, umat Tuhan menjadi bingung, banyak dari mereka menjadi gelisah, bahkan ada yang sampai disesatkan, dan lain-lain.

Topik tentang eskatologi sangat penting untuk diajarkan kepada siswa di sekolah agar mereka dapat mempersiapkan diri dengan sebaikbaiknya untuk menyambut kedatangan Tuhan Yesus yang kedua kali. Dalam pengajaran Pendidikan Agama Kristen (PAK) di sekolah, seharusnya topik atau pelajaran ini mendapat perhatian dan alokasi waktu yang cukup. Melalui topik atau pelajaran ini diharapkan dapat memperkuat keimanan siswa, menolong siswa untuk merubah sikap yang tidak sesuai dengan kehendak Allah dan menanamkan dalam diri siswa bahwa kelak ketika Tuhan Yesus datang untuk yang kedua kalinya, Ia akan mengadili manusia. Namun kenyataannya tidak seperti yang seharusnya. 
Pembelajaran tentang eskatologi hanya disinggung sepintas lalu ketika mengajarkan topik/materi yang ada kaitannya dengan eskatologi, misalnya kenaikan Tuhan Yesus ke sorga. Tidak ada topik khusus eskatologi dalam pengajaran PAK di sekolah. Berbeda dengan saudarasaudara kita di kalangan Muslim, di tingkat Sekolah Dasar saja, topik eskatologi yang mereka kenal dengan istilah "Hari Kiamat atau Hari Kemudian" benar-benar mendapat perhatian yang cukup, bahkan diajarkan antara dua sampai tiga kali, yakni pada kelas yang berbeda.

Berdasarkan latar belakang masalah di atas, maka penulis terdorong untuk mengkaji sejauh mana penerapan topik tentang akhir zaman dalam PAK sekolah, khususnyapada jenjang pendidikan dasar yakni Sekolah Dasar (SD) dan Sekolah Menengah Pertama (SMP).

\section{KAJIAN TEORITIS TENTANG ESKATOLOGI}

\section{Pengertian Eskatologi}

Kata "eskatologi" datang dari kata "eskaton" yang mengandung arti "yang akhir", dimana yang dimaksud tentunya mengacu kepada segala peristiwa yang terjadi menjelang, pada saat dan setelah kedatangan Tuhan Yesus yang kedua kali. Dengan demikian, eskatologi adalah ilmu yang mempelajari segala sesuatu yang terjadi menjelang, maupun saat bahkan setelah kedatangan Yesus kedua kali. $^{2}$

Eskatologi menurut ajaran Kristen terkait dengan pemenuhan janji Allah yaitu keselamatan yang sempurna di dalam Kristus. Harun Hadiwijono menyatakan:

Menurut Alkitab keselamatan pada zaman akhir ini memiliki dua segi, yaitu bahwa pada zaman akhir ini telah ada keselamatan, akan tetapi di lain pihak dikatakan juga bahwa keselamatan masih di depan kita atau belum ada. Maksudnya adalah keselamatan yang telah diberikan olehAllah kepada orang beriman, baru "untuk sementara waktu", belum sempurna. Apa yang telah ada sekarang ini belum sempurna. Akan tetapi apa yang telahada itu menjadi jaminan atau garansi, bahwa semua yang sempurna akandianugerahkan juga. ${ }^{3}$

Dengan demikian dapat dikatakan bahwa hidup orang beriman bukan diarahkan kepada hidup di dunia ini, melainkan kepada apa yang akan datang. Pengharapan

\footnotetext{
${ }^{2}$ http://www.sarapanpagi.org/eskatolog i-1-vt232.html

${ }^{3}$ Harun Hadiwijono, Iman Kristen (Jakarta: BPK Gunung Mulia, 2007),471
} 
orang beriman kepada Kristus harus diarahkan ke masa depan, yakni akhir zaman; zaman penuaian untuk memisahkan yang baik dan yang jahat (Mat. 13:39-40,49; 24:3; 28:20). Dalam Efesus 1:10, zaman itu disebut zaman kegenapan waktu untuk mempersatukan segala sesuatu di dalam Kristus sebagai Kepala, baik yang di sorga maupun yang di bumi. Oleh karena itu, dalam 1 dan 2 Tesalonika, serta 1 Korintus 15, kita dinasihatkan oleh rasul Paulus agar pengharapan kita orang beriman diarahkan kepada akhir zaman.Lebih lanjut lagi Hadiwijono menyatakan:

Hidup manusia sekarang ini (zaman akhir) dihubungkan dengan akhir zaman. Pada zaman akhir, kita diberi ciri dari keselamatan yang telahdikaruniakan kepada kita, tetapi yang belum secara sempurna menjadi milikkita. Sekalipun kita telah diselamatkan, namun kita masih harus berusaha untuk memegangnya (Fil. 3:12), berusaha dengan bersungguhsungguh di dalam peperangan iman untuk mencapai hidup kekal, yang menjadi tujuan panggilan kita (1 Tim. 6:12).

Kedatangan Kristus yang kedua kali adalah kedatangan untuk menghakimi orang yang hidup dan

\footnotetext{
${ }^{4}$ Ibid., 474.
}

yang mati. Karena itu, kedatangan Kristus yang kedua kali bukanlah suatu kejadian yang tiada sangkut pautnya dengan hidup sehari-hari pada zaman sekarang ini. Pada waktu itu segala sesuatu di dalam dunia ini akan dibuka tutupnya, akan dibuka kedoknya, di hadapan Allah. ${ }^{5}$

Menurut H. L. Willmington ${ }^{6}$, maksud kedatangan Kristus yang kedua kali adalah untuk:

1. Mengalahkan antikristus beserta bangsa-bangsa di dunia yang berkumpul di Harmagedon (bnd. Wahyu 19:17-21).

2. Mengumpulkan kembali, memperbaharui dan memulihkan umat Israel yang setia. (Yes. 43:5,6; Yer. 24:6; Yeh. 36:28; Amos 9:14,15; Mikha 7:18, 19; Mat. 24:31).

3. Menghakimi dan menghukum umat Israel yang tidak setia (Roma 9:6; 11:26; I Tes. 2:25,16; Yeh. 11:21 dan 20:38).

4. Memisahkan domba dan kambing (Mat. 25:31-46).

5. Mengikat iblis (Roma 16:20; Wahyu 20:1-3)

${ }^{5}$ Harun Hadiwijono, Inilah Sahadatku (Jakarta: BPK Gunung Mulia, 1995), 115116

${ }^{6}$ H. L. Willmington, Eskatologi (Malang: Gandum Mas, 1997), 265-282 
6. Membangkitkan orang-orang kudus dari zaman Perjanjian Lama dan dari masa siksaan (Ayub 19:25,26; Mz. 49:16; Yes. 25:8; 26:19; Dan. 12:2, Hosea 13:14; Yoh. 5:28-29; Ibr. 11:35; dan Wahyu 20:4,5).

7. Menghakimi malakat-malaikat yang jatuh (I Kor. 6:3; Luk. 8:3031; Mark. 1:23,24; dan Ef. 6:12).

\section{Beberapa Pandangan Pokok tentang Eskatologi}

Pada awal abad ke-21 ini, ilmu Perjanjian Baru mulai melihat secara baru bahwa pekabaran Yesus dan jemaat mula-mula adalah bersifat eskatologis. Berikut ini akan dipaparkan pandangan beberapa teolog mengenai eskatologi.

\section{J. Weiss}

Menurut J. Weiss, Yesus menantikan perubahan zaman yang akan berlangsung dengan segera sebagai hasil kegiatan Allah yang baru. Kerajaan Allah bukanlah suatu keadaan sempurna, yang lamakelamaan dicapai melalui perkembangan dunia yang berlangsungterus. Kerajaan Allah itu akan datang dengan tiba-tiba dari seberang melalui suatu bencana semesta alam yang mengerikan. ${ }^{7}$

\section{A. Schweitzer}

A. Schweitzer menekankan sifat futuris pekabaran Yesus. Dalam hal eskatologi, beliau menyatakan:

Segenap pikiran Yesus terarah pada kedatangan Kerajaan Allah dengan segera. Yesus sendiri akan sempat mengalaminya. Tetapi harapan itu tidak terkabul. Penantian-nantian apokaliptis terbentuknya Kerajaan Allah tidak tergenapi. Akibatnya besar! Karena seluruh pekabaran Yesus secara konsekuen bersifat eskatologis, maka secara konsekuen pula harus diambil kesimpulan: Yesus keliru, pengharapan dan sistem pengajaran-Nya tidak tepat. Memang kemudian, Schweitzer tidak benar-benar konsekuen, sebab masih mempertahankan beberapa segi wejangan etis Yesus yang intinya ialah "pengharapan terhadap hidup". 8

\section{H. Dodd}

Berbeda dengan pendapat Schweitzer, C. H. Dodd menekankan secara berat sebelah realized eschatology. Eskatologi Yesus, Paulus dan Yohanes bersifat presentis. Kerajaan Allah, keselamatan, kehidupan kekal sudah

${ }^{7}$ Ulrich Beyer, Garis-Garis Besar Eskatologi Dalam Perjanjian Baru (Jakarta: BPK Gunung Mulia, 2001), 1

${ }^{8}$ Ibid. 
terwujud kini dan disini. Jemaat mengharapkan tibanya akhir zaman sesudah kematian dan kebangkitan Yesus Kristus. $^{9}$

\section{Rudolf Bultmann}

Pandangan R. Bultmann dan sebagian murid-muridnya mengenai eskatologi berkaitan dengan pengertian tentang sejarah. Sejarah tidak hanya diartikan sebagai suatu rentetan zaman yang berturut-turut. Sejarah lebih mengartikan kesejarahan eksistensi manusia. Yang dimaksud ialah sejarah hidup yang dialami setiap manusia dan yang mengandung kedua kemungkinan, yaitu dapat atau tidak menemui kepribadian yang sejati.

Dalam kaitannya dengan eskatologi, Bultmann berpendapat bahwa orang percaya hidup dari dan di dalam Kristus. Dan karena Kristus adalah "penyudah sejarah" (Roma 10:4), maka orang yang hidup "dalam Kristus" sudah menghadapi akhir sejarah dan telah memasuki eskaton. $^{10}$

\section{OscarCullmann}

Cullmann mengembangkan pengertiannya yang temporal tentang

${ }^{9}$ Ibid., 2

${ }^{10}$ Ibid. eskatologi PB dengan memperdebatkan secara kritis pandangan-pandangan tersebut di atas. Cullmann menyatakan:

Eskatologi sudah genap realisasinya, belum kelihatan kesempurnaannya. Ibarat suatu perang, pertempuran yang menentukan sudah berlalu; "victory day", yaitu hari kemenangan, sudah tiba, tetapi gencatan senjata belum dilaksanakan oleh kedua belah pihak yang telah berperang itu, sehingga disana sini masih berlangsung beberapa perkelahian kecil. Hari kemenangan sudah tiba dengan kedatangan serta karya Yesus Kristus dan sekarang kita sudah ditebus. Tetapi, pada pihak lain, dosa masih berpengaruh, maut belum ditiadakan, dan seluruh dunia tampaknya memang belum dikuasai oleh kemenangan Tuhan Yesus Kristus. ${ }^{11}$

\section{Kapan Mulainya Eskatologi?}

Harun Hadiwijono mengatakan, bahwa eskatologi itu mulai dengan kelahiran Tuhan Yesus Kristus hingga sekarang dan seterusnya. ${ }^{12}$ Agak senada dengan itu, Ulrich Beyer menyatakan bahwa dengan kematian dan kebangkitan Yesus sudah berlangsung kejadian eskatologis yang menentukan. ${ }^{13}$ Sedangkan

\footnotetext{
${ }^{11}$ Ibid., 3-4

${ }^{12}$ Hadiwijono, "Iman Kristen”, Op. cit., 473

${ }^{13}$ Beyer, Op.cit., 24
} 
menurut ajaran aliran-aliran

Pentakosta, eskatologi itu mulai ketika kedatangan Kristus kembali yang pertama dan memerintah di bumi ini selama seribu tahun. ${ }^{14}$

Para kaum Khiliast dan

Millenialis mengajarkan,

Kelak pada akhir zaman Kristus akan datang kembali dua kali. Kedatangan-Nya kembali yang pertama diperlukan untuk memerintah sebagai Raja atas dunia ini, bersama-sama dengan para orang beriman selama seribu tahun. Selama seribu tahun ini Iblis diikat dengan rantai dan dilemparkan ke dalam jurang maut. Akan tetapi pada akhir seribu tahun itu Iblis dilepaskan dari ikatan rantainya lalu menyesatkan segala bangsa, guna memerangi para orang beriman. Tuhan Yesus yang telah memerintah seribu tahun tadi, naik ke sorga lagi, sekarang datang kembali untuk kedua kalinya, guna menghakimi segala manusia. ${ }^{15}$

Ajaran ini didasarkan atas penafsiran secara harafiah Wahyu 20.

Atas ajaran para kaum Khiliast ini, Harun Hadiwijono berkeyakinan:

Pandangan yang demikian tidak sesuai dengan gagasan yang terkandung dalam kitab Wahyu sendiri. Menurutnya, suatu wahyu dalam Alkitab, tidak pernah memberikan laporan 490

${ }^{14}$ Hadiwijono, "Iman Kristen", Op. cit.,

${ }^{15}$ Ibid., 491 mengenai urutan peristiwa yang akan terjadi. Kitab Wahyu adalah suatu pernyataan atau suatu pengambilan tutup yang menutupi keselamatan yang dikaruniakan di dalam Kristus. Kitab wahyu bukan diberikan untuk memberi kepuasan kepada keinginan kita untuk mengetahui yang akan terjadi. Segala gambaran yang diberikan di dalam kitab Wahyu adalah 'gambaran wahyu' .... bahwa orang beriman sekarang ini sudah turut memerintah bersamasama dengan Kristus. ${ }^{16}$

Senada dengan itu, H. L. Willmington mengemukakan, "...banyak orang telah menyatakan bahwa karena angka ini hanya terdapat dalam satu bagian Perjanjian Baru, maka orang tidak dapat memastikan bahwa masa seribu tahun akan benar-benar menjadi kenyataan. Untuk menekankan maksud tersebut, mereka mengacu pada 2 Petrus 3:8, '... di hadapan Tuhan satu hari sama seperti seribu tahun dan seribu tahun sama seperti satu hari.",17

Maksud dari kerajaan seribu tahun $^{18}$ adalah :

1. Untuk membalas perbuatan orangorang kudus Allah (Mzm. 58:12; Ams. 11:18; Yes. 40:10; Mat.

\footnotetext{
${ }^{16}$ Ibid.

${ }^{17}$ Willmington, Op.cit., 285

${ }^{18}$ Ibid., 288-291
} 
16:27; 35:34; Kol. 3:24 dan Why. 22:12).

2. Untuk menjawab doa contoh yang sering dipanjatkan (Luk. 11:1-4 dan Mat. 6:9-13).

3. Untuk menebus ciptaan (Rm. 8:1922).

4. Untuk memenuhi tiga perjanjian penting di dalam Perjanjian Lama yaitu janji Allah kepada Abraham, perjanjian yang menyangkut Daud dan perjanjian baru.

5. Untuk membuktikan satu hal yaitu bagaimana pun lingkungan atau keturunan seseorang, jika terpisah dari kasih karunia Allah, manusia pasti akan gagal (Kej. 3; 6; 11; Kel. 1; Mat. 27; I Tim. 4; Why. 19 dan Why. 20).

6. Untuk menggenapi pokok utama dari nubuat dalam Alkitab (I Ptr. $1: 1)$.

ESKATOLOGI DAN

PENERAPANNYA DALAM

PELAJARAN PENDIDIKAN

AGAMA KRISTEN DI SEKOLAH

\section{Hakikat dan Tujuan PAK}

Pendidikan Agama Kristen pada prinsipnya berorientasi pada pengertian kekristenan, yaitu pendidikan yang berpusat pada Kristus. B. Samuel Sidjabat mengutip pandangan Robert W. Pazmino memberikan definisi tentang pendidikan Agama Kristen sebagai berikut:

Pendidikan Kristen merupakan usaha bersahaja dan sistematis, ditopang oleh upaya rohani dan manusiawi untuk mentransmisikan pengetahuan, nilai-nilai, sikap-sikap, keterampilan-keterampilan dan tingkah laku yang bersesuaian dengan iman Kristen; mengupayakan perubahan, pembaharuan dan reformasi pribadi, kelompok bahkan struktur oleh kuasa Roh Kudus, sehingga peserta didik hidup sesuai dengan kehendak Allah sebagaimana dinyatakan oleh Alkitab, terutama dalam Yesus Kristus. ${ }^{19}$

Hakikat PAK di atas merupakan pengembangan dari arti PAK yang dirumuskan oleh E. G. Homrighausen dan I. H. Enklaar pada Konferensi PAK di Sukabumi pada tahun 1955 sebagai berikut:

Inilah arti sedalam-dalamnya dari PAK, bahwa dengan menerima pendidikan itu, segala pelajar, muda dan tua, memasuki persekutuan iman yang hidup dengan Tuhan sendiri, dan oleh dan dalam Dia mereka terhisab pula pada persekutuan jemaatNya yang mengakui dan

\footnotetext{
${ }^{19}$ B. Samuel Sidjabat, Strategi Pendidikan Kristen (Yogyakarta: Andi Offset, 1994), 10
} 
mempermuliakan Nama-Nya di segala waktu dan tempat.",20

Jadi, PAK di sekolah pada hakikatnya adalah pendidikan yang diberikan secara terencana, sistematis dan kontinu kepada setiap peserta didik agar memahami kasih dan karya Allah dalam hidupnya dan membantu peserta didik dalam mentransformasikan nilai-nilai Kristiani dalam kehidupan seharihari.

Konferensi Kurikulum I PAK yang diselenggarakan oleh KOMPAK DGI di Sukabumi, 12 Juni s/d 14 Juli 1963, merumuskan tujuan PAK sebagai berikut:

Mengajak, membantu, menghantar seseorang untuk mengenal akan kasih Allah yang nyata dalam Yesus Kristus, sehingga dengan pimpinan Roh Kudus, ia datang ke dalam satu persekutuan hidup pribadi dengan Tuhan. Hal ini dinyatatakan dalam kasihnya kepada Allah dan sesamanya manusia yang dihayatinya dalam hidupnya sehari-hari, baik dengan kata-kata, maupun dengan perbuatan selaku anggota Tubuh Kristus. $^{21}$

\footnotetext{
${ }^{20}$ E. G. Homrighausen dan I. H. Enklaar, Pendidikan Agama Kristen (Jakarta: BPK Gunung Mulia, 2004), 26 ${ }^{21}$ Jedida T. Posumah-Santosa, Pendidikan Agama Kristen di Sekolah dalam Andar Ismail (Peny.), Ajarlah Mereka Melakukan (Jakarta: BPK Gunung Mulia, 2004), 158
}

Rumusan di atas kemudian berubah sebagaimana yang dirumuskan dalam Seminar PAK di Jakarta, pada tanggal $22-25$ Februari 1988 yang diselenggarakan oleh PGI (Persekutuan Gereja-gereja di Indonesia) dalam kerjasama dengan MPPK (Majelis Pusat Pendidikan Kristen di Indonesia), PERSETIA (Perhimpunan Sekolahsekolah Tinggi Theologia di Indonesia) dan BK-PTKI (Badan Kerjasama Perguruan Tinggi Kristen di Indonesia) sebagai berikut:

PAK sebagai tugas panggilan gereja adalah usaha untuk menumbuhkan dan mengembangkan kemampuan peserta didik agar dengan pertolongan Roh Kudus dapat memahami dan menghayati Kasih Allah dalam Yesus Kristus, yang dinyatakannya dalam kehidupan sehari-hari, terhadap sesama dan lingkungan hidupnya. ${ }^{22}$

Kemudian, Oditha Hutabarat dan Wiwik Estiawan merumuskan tujuan PAK di sekolah dengan sedikit memodifikasi tujuan PAK di atas sebagai berikut:

PAK adalah usaha yang dilakukan secara terencana dan kontinu dalam rangka mengembangkan kemampuan pada siswa agar dengan

${ }^{22}$ Ibid., 157 
pertolongan Roh Kudus dapat memahami dan menghayati kasih Allah di dalam Yesus Kristus yang dinyatakannya dalam kehidupan sehari-hari, terhadap sesama dan lingkungannya. ${ }^{23}$

Berdasarkan tujuan PAK di atas, dapat ditarik tiga inti tujuan PAK di sekolah $^{24}$ sebagai berikut:

1. Memperkenalkan Allah Bapa, Putera dan Roh Kudus dan karyakarya-Nya.

2. Menghasilkan manusia Indonesia yang mampu menghayati imannya secara bertanggung jawab di tengah masyarakat yang pluralistik.

3. Menanamkan pemahaman tentang Allah dan Karya-Nya kepada siswa, sehingga mampu memahami dan menghayati karya Allah dalam hidup manusia.

\section{Eskatologi Dalam Kurikulum PAK di Tingkat Sekolah Dasar dan Menengah Pertama}

Seperti yang telah dikemukakan pada bagian pendahuluan bahwa pengajaran tentang eskatologi dalam PAK di sekolah, khususnya di SD

23 Oditha Hutabarat dan Wiwik Estiawan, Kurikulum Pendidikan Agama Kristen BerbasisKompetensi Sekolah Dasar(Jakarta: Bagian Proyek Peningkatan Wawasan KependidikanGuru Agama Ditjen Dikdasmen Depdiknas, 2003), 3

${ }^{24}$ Ibid., 3-4. dan SMP sangat penting tetapi masih kurang mendapat perhatian. Mungkin penyebabnya adalah topik eskatologi tidak tercantum secara tersurat dalam kurikulum. Jika kita memerhatikan dengan saksama, kurikulum PAK baik di tingkat SD maupun SMP, mulai dari kurikulum 1994 yang dikenal dengan kurikulum CBSA sampai suplemen kurikulum 1999, topik eskatologi tidak dicantumkan secara khusus dalam materi pengajaran. Demikian halnya dalam kurikulum 2004 yang dikenal dengan sebutan Kurikulum Berbasis Kompetensi (KBK) sampai kurikulum 2006 yang dikenal dengan sebutan Kurikulum Tingkat Satuan Pendidikan (KTSP), topik eskatologi juga tidak tercantum dalam Standar Kompetensi (SK) maupun dalam Kompetensi Dasar (KD).

Namun demikian, hendaknya guru PAK jeli dan tanggap melihat peluang untuk memasukkan topik eskatologi ini dalam pengajaran PAK di sekolah. Alasannya adalah, Kurikulum Tingkat Satuan Pendidikan (KTSP) memberi peluang bagi guru untuk mendesain materi pengajaran sedemikian rupa karena KTSP disusun dan dilaksanakan oleh 
masing-masing satuan pendidikan (sekolah) berdasarkan konteks dan karakteristik masing-masing dengan tetap berpedoman pada Standar Isi, yang dijabarkan ke dalam Standar Kompetensi (SK) dan Kompetensi Dasar (KD) yang telah ditetapkan oleh Badan Nasional Standar Pendidikan (BNSP). Penyusunan materi pengajaran, di samping mengacu pada SK dan KD tersebut, juga harus mempertimbangkan keunikan peserta didik, kontekstualisasi serta stakeholder sekolah. Karena itu, ke depan diharapkan bahwa topik eskatologidijadikan sebagai salah satu materi pokok dengan menyisipkan topik tersebut pada SK dan KD yang terkait misalnya pada SK dan KD tentang karya penyelamatan Tuhan Yesus, sehingga topik ini benar-benar dapat termuat dalam kurikulum dan diajarkan secara terencana dan terinci dalam PAK di sekolah dengan alokasi waktu yang cukup.

\section{Pengajaran tentang Eskatologi dalam PAK di Sekolah}

Sekalipun kita tidak mengetahui waktu yang tepat tentang kapan Tuhan Yesus datang kembali, namun kita perlu memiliki sikap yang benar dalam menyambut kedatanganNya. Hal ini perlu ditegaskan dalam pengajaran tentang eskatologi dalam PAK karena tidak sedikit orang yang mengambil sikap yang salah. Kesalahan yang dilakukan misalnya oleh Pdt. Mangapin dan jemaatnya beberapa tahun lalu, bukanlah yang pertama kali. Sebenarnya, sejarah gereja telah berulang kali menyaksikan adanya kesalahan yang sama di seluruh dunia dilakukan oleh orang-orang yang sesat dalam ketulusannya. Itulah sebabnya dalam khotbah-Nya tentang akhir zaman, Tuhan Yesus tidak lupa menegaskan sikap yang benar yang harus dilakukan oleh umatNya dalam menanti kedatangan-Nya.

Dengan mengacu pada pengajaran Tuhan Yesus sendiri, maka dalam pengajaran PAK di sekolah tentang topik eskatologi, ada beberapa hal yang perlu ditekankan yaitu:

1. Nasihat untuk berjaga-jaga. Kita harus berjaga-jaga karena sebagaimana disebut di atas, kedatangan-Nya kelak tidak terduga sebelumnya. Segala sesuatu berjalan secara rutin, sebagaimana kehidupan normal sehari-hari berlangsung. 
Tuhan Yesus bersabda: "Sebab sebagaimana mereka pada zaman sebelum air bah itu makan dan minum, kawin dan mengawinkan, sampai kepada hari Nuh masuk ke dalam bahtera, dan mereka tidak tahu akan sesuatu, demikian pulalah halnya kelak pada kedatangan Anak Manusia” (Mat.24:38,39).

2. Bekerja dengan setia. Tuhan tidak menginginkan kita menanti dengan pasif, tetapi harus aktif dengan melakukan segala tugas yang telah dipercayakan-Nya kepada kita, termasuk tugas untuk belajar sebagai seorang siswa. Tidak ada tugas dan pekerjaan yang kurang mulia bila kita kerjakan dalam Dia. Untuk itulah Tuhan Yesus memberikan perumpamaan tentang hamba yang setia dan jahat pada Matius 24:45-51. Rasul Paulus juga mengingatkan kita agar melakukan segala sesuatu seperti untuk Tuhan dan bukan untuk manusia (Kol.3: 23).

3. Pelita kita harus tetap menyala. Sungguh menyedihkan gambaran tentang gadis bodoh yang diberikan Tuhan Yesus dalam Matius 25:1-13. Mereka telah lama menanti dan merindukan kedatangan mempelai laki-laki tersebut. Namun pada saat yang dirindukan tersebut tiba, mereka tidak siap menyambutnya, karena pelita mereka tidak menyala. Mereka kekurangan minyak untuk menyalakan pelita tersebut. Konteks perumpamaan tersebut jelas, yaitu mengenai kedatangan Tuhan Yesus kembali di akhir zaman. Karena itu, kita juga jangan sampai seperti gadis bodoh tersebut. Kita harus seperti gadis yang bijaksana tersebut yang pe-litanya tetap menyala. Alkitab menegaskan, "Janganlah hendaknya kerajinanmu kendor, biarlah rohmu menyala-nyala dan layanilah Tuhan" (Rm.12:11). Karena itu, kita harus terus menerus memelihara hubungan pribadi kita dengan-Nya melalui doa dan pembacaan firman Tuhan tiap-tiap hari, serta tekun bersekutu dan beribadah dengan motivasi yang benar.

4. Mengembangkan talenta yang diberikan Tuhan. Dalam perumpamaan Tuhan Yesus tentang talenta dalam Matius 25:14-30, jelas dituntut kesetiaan. Sangat penting ditegaskan bahwa masalahnya bukanlah berapa banyak talenta yang kita miliki dan berapa banyak yang dihasilkan ketika 
mengembangkannya,

tetapi

bagaimana sikap kita terhadap talenta tersebut. Kiranya dalam anugerahNya kita juga boleh mendengar pujian Tuhan Yesus berikut: "Baik sekali perbuatanmu itu, hai hambaKu yang baik dan setia; engkau telah setia dalam perkara kecil, aku akan memberikan kepadamu tanggung jawab dalam perkara yang besar. Masuklah dan turutlah dalam kebahagiaan tuanmu" (Mat. 25:21). ${ }^{25}$

5. Keempat hal tersebut di atas perlu mendapat penekanan dalam pengajaran PAK di sekolah untuk mengantar siswa tiba pada satu titik puncak pemahaman dan penghayatan bahwa ketika Tuhan Yesus datang untuk yang kedua kalinya kelak, Ia akan menjadi Hakim yang mengadili semua umat manusia. Penegasan ini diharapkan dapat mempersiapkan diri siswa sedini mungkin untuk meyambut kedatanganNya yang kedua kali sehingga dalam diri siswa dan orang percaya umumnya sungguh-sungguh menyadari dan memahami bahwa apa yang kita perbuat di dunia ini, kelak akan kita pertanggungjawabkan masing-masing di hadapan Tuhan Yesus. Doktrin

\footnotetext{
${ }^{25}$ http://www.sarapanpagi.org/akhirzaman-akhir-zaman-vt255.html
}

tentang eskatologi dalam Perjanjian Baru harus ditanamkan dalam diri siswa di sekolah sedini mungkin supaya mereka belajar untuk hidup berdasarkan kehendak Allah dan menjauhi atau meninggalkan bentukbentuk kehidupan yang tidak berkenan kepada Allah.

\section{KESIMPULAN}

Berdasarkan pemaparan singkat di atas, maka penulis menyimpulkan:

Pertama, pengajaran tentang eskatologi dalam PAK di sekolah khususnya di SD dan SMP sangat penting tetapi masih sangat kurang mendapat perhatian. Hal itu jelas bila kita memerhatikan kurikulum PAK yang tidak mencantumkan topik eskatologi sebagai salah satu materi pokok.

Kedua, dalam rangka pengimplementasian topik eskatologi dalam pengajaran PAK di sekolah, maka hal-hal yang harus ditekankan adalah nasihat untuk berjaga-jaga, bekerja dengan setia, pelita kita harus tetap menyala dan mengembangkan talenta yang diberikan oleh Tuhan.

Berdasarkan kesimpulan di atas, maka penulis memberikan saransaran sebagai berikut: 
Pertama, hendaknya guru PAK jeli dan tanggap melihat peluang untuk memasukkan topik eskatologi ini dalam pengajaran PAK di sekolah karena kurikulum memberikan peluang untuk hal itu dengan menyisipkannya pada SK dan KD yang terkait.

Kedua, dalam pengajaran tentang topik eskatologi kepada siswa di sekolah, hendaknya guru PAK benarbenar menekankan: nasihat untuk berjaga-jaga; bekerja dengan setia; pelita kita harus tetap menyala; dan mengembangkan talenta yang diberikan oleh Tuhan sebagai persiapan untuk menyambut kedatangan Tuhan Yesus yang kedua kalinya.

\section{DAFTAR PUSTAKA}

Beyer, Ulrich. Garis-Garis Besar Eskatologi Dalam Perjanjian Baru, Jakarta: BPK Gunung Mulia, 2001.

Hadiwijono, Harun. Iman Kristen, Jakarta: BPK Gunung Mulia, 2007.

\section{.Inilah Sahadatku,} Jakarta: BPK Gunung Mulia, 1995.

Homrighausen, E. G. dan I. H. Enklaar.Pendidikan Agama Kristen. Jakarta: BPK Gunung Mulia, 2004
Hutabarat, Oditha dan Wiwik Estiawan.Kurikulum

Pendidikan Agama

KristenBerbasis Kompetensi

Sekolah Dasar,Jakarta: Bagian

Proyek PeningkatanWawasan

Kependidikan Guru Agama

Ditjen Dikdasmen Depdiknas, 2003.

Ismail (Peny.). Ajarlah Mereka

Melakukan, Jakarta: BPK

Gunung Mulia, 2004.

Sidjabat, B. Samuel.Strategi

Pendidikan Kristen, Yogyakarta:

Andi Offset, 1994.

Willmington, H. L.Eskatologi, Malang: Gandum Mas, 1997.

http://www.sarapanpagi.org/eskatolog i-1-vt232.html

http://www.sarapanpagi.org/akhirzaman-akhir-zaman-vt255.html 